\title{
Phytochemical Screening and Antimicrobial Activity of Curcuma longa Natural Dye
}

\author{
Chairman $\mathrm{K}^{1 *}$, Jayamala $\mathbf{M}^{2}$, Vijila Christy $\mathbf{R}^{1}$ and Ranjit Singh AJA ${ }^{3,4}$
}

${ }^{1}$ Department of Microbiology, Kamarajar Govt. Arts College, Surandai, Manonmaniam Sundaranar University, Tirunelveli, 627 859, Tamilnadu, India ${ }^{2}$ Department of Biotechnology, Manonmaniam Sundaranar University, Alwarkurichi, Tirunelveli, Tamilnadu, India

${ }^{3}$ Department of Chemistry, Sri Paramakalyani College, Alwarkurichi, Manonmaniam Sundaranar University, Tirunelveli, Tamilnadu, 627 412, India

${ }^{4} \mathrm{JP}$ Arts and Science College, Ayikudi, Tenkasi, Tirunelveli District, Tamilnadu, India

\begin{abstract}
Spectrometric and antimicrobial activities of natural colourants and dyed silk have been studied. Textile materials and clothing are known to be susceptible to microbial attack, as these provide large surface area and absorb moisture required for microbial growth. Natural dye Curcuma longa were tested against common pathogens Escherichia coli and Staphylococcus aureus. Curcuma longa dye was most effective and showed maximum zone of inhibition thereby indicating best antimicrobial activity against all the microbes tested. These textiles dyed with these natural dyes can be very useful in developing clothing for infants, elderly and infirm people to protect them against common infections.
\end{abstract}

\section{Keywords: Antimicrobial activity; Textile; Natural dye}

\section{Introduction}

The use of non-allergic, non-toxic and eco-friendly natural dyes has become a matter of significant importance due to the increased environmental awareness in order to avoid some hazardous synthetic dyes. Dyes are applied to various substrates (textiles, leather, paper, hair etc.) from liquid in which they are completely, or at least partially soluble [1], and may require a mordant to improve its fastness on the fibre. Curcuma longa, commonly known as Turmeric is a tropical perennial herb belonging to the family Zingiberacea. It is related to ginger and is grown throughout India, other parts of Asia and Africa [2]. Turmeric is commonly used as a spice and result in a bright yellow powder valued as a natural food dye [3]. Plant by-products (carrot, onion, black carrot, sage, spinach and thyme) were investigated in the form of aqueous extracts for dyeing capacity on fibres, colorant and antioxidant potential using colorimetric, chromatographic tools, and FTC assay, respectively.

Sharma et al. explored the herbaceous plant Eupatorium adenophorum as a very good green color source for dyeing of silk yarn with excellent fastness properties [4]. Leaves of the Eupatorium plants were collected and shade dried, crushed and packed. Sericin was removed so as not to interfere with luster and dye absorption. Tawfik explained the suitability of turmeric in the fine powder form as natural dye in printing cotton, polyester and their blended fabrics using pigment-printing technique. Variable studied included concentration of the colour, nature of thickening agent, type of fixation and $\mathrm{pH}$ of the printing paste. The printed goods were evaluated by measuring the K/S and the overall fastness properties [5]. Samanta et al. performed work on cotton fabric dyed with four different natural dyes (turmeric, myrobolan, madder, red sandalwood) using pre, post and simultaneous-mordanting techniques for dyeing [6].

Textile processing industry is one of the major environmental polluters. In order to process a ton of textile, one might have to use as much as 230 to 270 tons of water. The effluent generated by this much water would pollute the environment as it contains a heavy load of chemicals including dyes used during textile processing. Over $7 \times 10^{5}$ tonnes and approximately 10,000 different types of dyes and pigments are produced world-wide annually. It is estimated that $10-15 \%$ of the dye is lost in the effluent during the dyeing process [7].
Thus, there are two main ways to limit the environmental impact of textile processing. One is to construct sufficiently large and highly effective effluent treatment plants, and the other way is to make use of dyes and chemicals that are environment friendly. Natural dyes are mostly eco-friendly, biodegradable, less toxic, and less allergenic as compared to synthetic dyes. However, studies have shown that certain natural dyes may have detectable mutagenic effects e.g., elderberry colour and safflower yellow; others, like carmine, can cause asthma by continuous inhalation, but it can be said that most of the natural dyes are safe and some even have curative effect e.g., curcumin in turmeric has antibacterial [8]. Most of the studies conducted earlier have reported the activity of plant materials against Candida rugosa, Staphylococcus aureus and other drug resistant bacteria [9]. Production of concentrated natural dyes is a pre-requisite for a re-introduction of plant colorant based dyes into modern textile dyeing operations [10].

\section{Turmeric (Curcuma longa):}

Turmeric (Curcuma longa) is a plant native to south India and Indonasia. It is also cultivated in China and the whole of South East Asia. It is also called "Haldi". Its tuberous rhizomes have been used as a condiment, a colourant and an aromatic stimulant since antiquity. Turmeric consists of various molecular constituents, including three gold colour alkaloidal curcuminoid, curcumidesmethoxy curcumin and bisdemethoxy curcumin. The curcuminoid content responsible for colour, depends upon the turmeric variety and within a variety on the maturity at harvest. It may be present to the extent of 4 to $8 \%$ in turmeric harvesting at the right maturity being an important factor for colour and aroma. Some isomeric forms of curcumin are displayed below (Figure 1):

*Corresponding author: Chairman K, Department of Microbiology, Kamarajar Govt. Arts College, Surandai, Manonmaniam Sundaranar University, Tirunelveli, Tamilnadu, 627 859, India, Tel: 09659733813; E-mail: journalpublish2012@gmail.com

Received November 25, 2014; Accepted March 02, 2015; Published March 07, 2015.

Citation: Chairman K, Jayamala M, Christy VR, Singh RAJA (2015) Phytochemical Screening and Antimicrobial Activity of Curcuma longa Natural Dye. General Med 3: 171. doi:10.4172/2327-5146.1000171

Copyright: (c) 2015 Chairman K, et al. This is an open-access article distributed under the terms of the Creative Commons Attribution License, which permits unrestricted use, distribution, and reproduction in any medium, provided the original author and source are credited. 


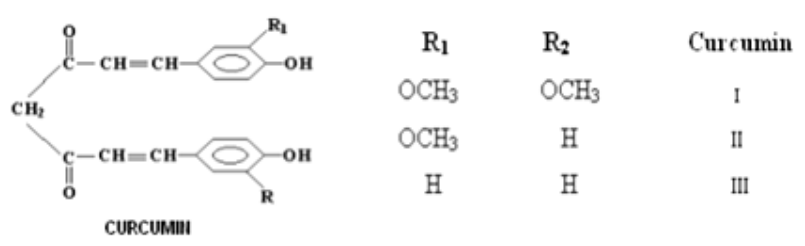

Isomeric forms of Curcumin

Figure 1: Isomeric forms of curcumin.

Curcumin has anti-inflammatory, antifungal and anti-tumorous. It is also widly used as food colourant. It is called C.I Natural Yellow 3, WHO (World Health Organization) and FAO (Food and Agricultural Organization) committees have approved it as food additive, its colour index number is C.I, 75300, E100 [11]. The plant of turmeric is given in Figure $2 a$ and $2 b$ ).

\section{Experimental}

\section{Preparation of extract}

The powders of Curcuma longa were purchased from a local market in supermarket, Tirunelveli, Tamilnadu. The dry powder of the plant was weighed using an electric weighing scale. These were then soaked in ethanol for 24 hours undisturbed. The extraction was preceded using the Soxhlet extractor. The extract was then transferred to a rotatory evaporator. There was further drying of the extract in a drying oven at $60^{\circ} \mathrm{C}$. The temperature enabled the preservation of the active ingredients of the extract after it was obtained in powdered form.

\section{Preliminary phytochemical screening}

The extract of Curcuma longa was screened to determine the presence of the following metabolites through preliminary phytochemical screening. Alkaloids were detected using the Dragendoff's reagent, Mayer's reagent, Wagner's reagent and tannic acid. Flavonoids were determined by the ferric chloride test, lead acetate test, sodium hydroxide test and ethyl acetate test. Tannin detection was by ferric chloride test and bromine water test, while phlobotannins was with hydrochloric acid. Saponin was determined with the froth tests and haemolytic test.

\section{Method of mordanting}

The dyeing experiments were carried out with silk yarn by adopting pre-mordanting technique (Gulrajani and Gupta, 1992) i.e. the samples were treated with different metal salt solutions before dyeing. Silk yarn (0.5 g) was dipped in $20 \mathrm{ml}$ of prepared $4 \%$ mordant solution at 1:30 MLR (material to liquor ratio) at $60-70^{\circ} \mathrm{C}$ for $30-45^{\circ} \mathrm{C}$ min. Then the mordanted yarn was air dried for $15 \mathrm{~min}$. The dye solution was prepared 1:30 MLR (material to liquor ratio) with $5 \%$ dye and the mordanted silk yarn was then dipped in $20 \mathrm{ml}$ of dye solution for $30-45^{\circ} \mathrm{C}$ min at $60-70^{\circ} \mathrm{C}$. The dyed yarn was left for $15 \mathrm{~min}$ for air oxidation. The dyed yarns were washed with cold water followed by soap solution and then washed thoroughly with water. The wet samples were dried at room temperature.

\section{Absorbance measurements}

The ultraviolet/visible (UV/Vis) absorption measurement was recorded for the determination of absorption (\%) on Perkin Elmer, Lambda $35 \mathrm{UV} / \mathrm{Vis}$ spectrophotometer in the wavelength range 200-
$800 \mathrm{~nm}$. The absorbance of 5\% dye solution was recorded before and after dyeing the silk yarn at an average of three measurements. The amount of dye absorbed was calculated by using the relation (Figure 3) [12]:

\section{Antimicrobial screening test}

Investigations were carried out to determine the antibacterial activity of the dyes by using five different concentrations of each dye solution i.e. $20,40,60$ and $80 \mathrm{mg} / \mu \mathrm{l}$ which is equivalent to $2,4,6$, and $8 \%$ dye solution respectively. The antimicrobial (both bacterial and fungal) studies were carried out in triplicates using standard methods (ATCC method 30) and a control set was run along with each test. The test bacteria (S. aureus and E. coli) were streaked closely and gently on sterile nutrient agar plates. $30 \mathrm{ml}$ of dye solution was added on the sterilized filter disc, which is placed on the top of the seeded medium. After overnight incubation at $37^{\circ} \mathrm{C}$, the zone of inhibition was measured by taking the average of the zones obtained from the triplicate plates. Anti-fungal activities of the dyes against C. albicans and A. niger have been detected on sterile Potato Dextrose Agar plates. Experiments were carried out at five different concentrations of each dye in a similar way as described above. After incubation at room temperature (ranging between 25 and $30^{\circ} \mathrm{C}$ for $72 \mathrm{~h}$, the zone of inhibition was measured.

\section{Results and Discussion}

Phytochemical screening of the dye confirmed the presence of saponins, tannins, flavonoids and alkaloids. Among these compounds,

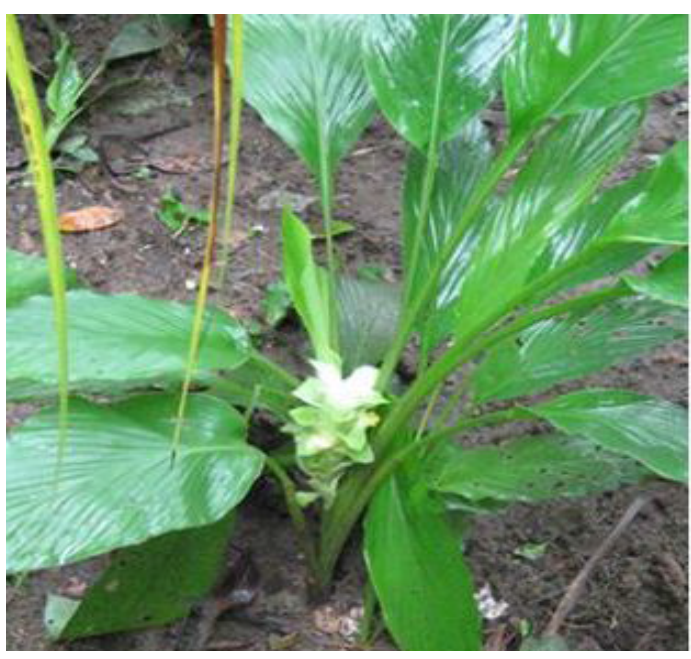

Figure 2a: Curcuma longa plant.

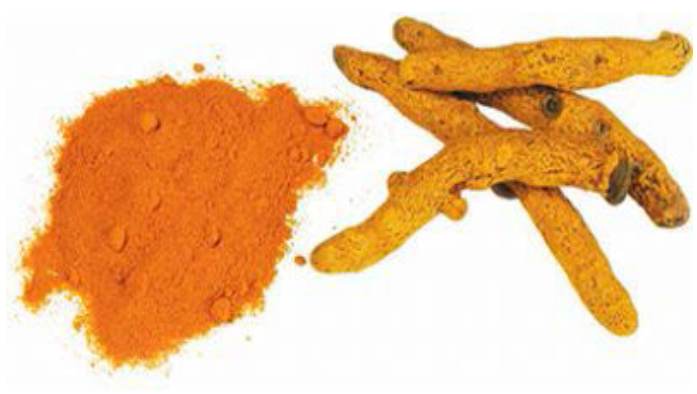

Figure 2b: Curcuma longa rhizome powder. 


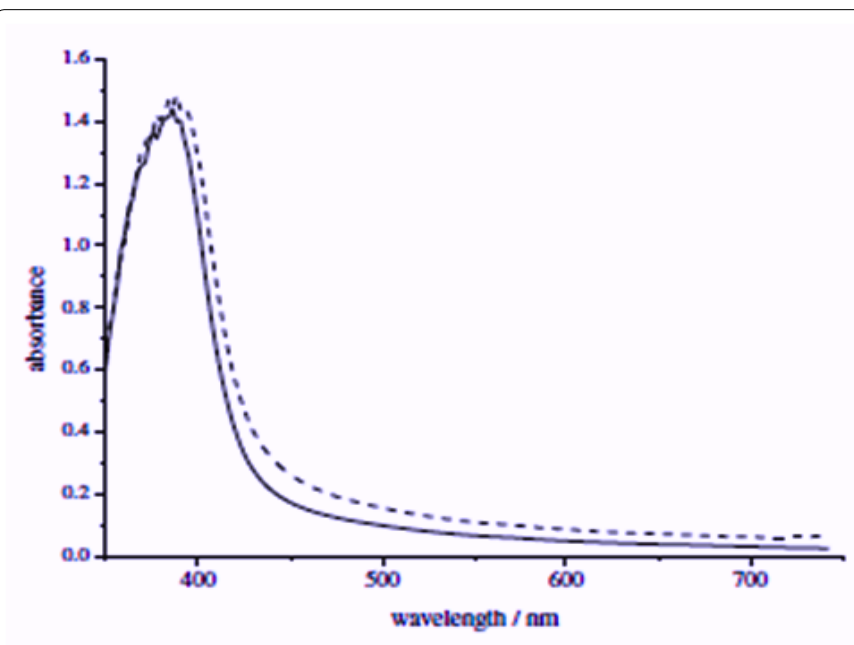

Figure 3: UV-Spectroscopy analysis of Curcuma longa crude extracts.

tannins and flavonoids are the substances which can give the colour. Tannins are the most important ingredients which are necessary for dyeing.

Antibacterial activity of dye solutions the crude dye extract of Curcuma longa and the separated components of the plant studied revealed the presence of bioactive properties. Results of the disc diffusion method of Curcuma longa are summarized in Table 1. MIC values of the crude dye extract and the separated components against $S$. aureus and E. coli has been depicted in Table 2. Antibacterial activity of the dyed fabrics having studied the antimicrobial activity of dyes in solution, the next step was to assess their effectiveness on dyed fabrics. Qualitative and quantitative investigations were carried out on textile substrates -cotton, wool, silk, nylon, polyester and acrylic dyed with $10 \%$ and $15 \%, 20 \%$, and $25 \%$ shade. The results of disc diffusion method showed that none of the dyed fabrics showed a zone of inhibition against $S$. aureus or E. coli at the test concentrations.

Antibacterial activity of dyed fabrics was then quantitatively assessed to determine the percentage reduction in bacterial populations in liquid media. MIC of the dyed fabrics against the tested bacterial organisms is shown in Table 3. The Curcuma longa natural dyes are prepared and analyzed absorbance and transmittance in using UVVisible Spectrophotometer.

The light fastness of the dyed samples were in the range from poor to fairly good. The poor light fastness can be attributed to the inherent property of the dye chromophore to photochemical oxidation [13].

Shenai studied the dyeing of cotton fabric using Eclipta as natural dye in both conventional and sonicator methods. The effects of dyeing show higher color strength values obtained by the latter. Dyeing kinetics of cotton fabrics were compared for both the methods. The time/dye uptake reveals the enhanced dye uptake showing sonicator efficiency. The results of fastness properties of the dyed fabrics were fair to good [14].

Vankar et al. investigated Plant materials which are available from farming regions in the moderate Austrian climate to serve as sources for natural dyes in textile dyeing operations [15]. The extraction of the dye components from the plant materials was performed with boiling water without addition of chemicals or solvents. Based upon a rigorous selection of possible plant sources, a selection of natural dyestuffs applicable in a one-bath dyeing step was established. A broad variation in shade and color depth can be achieved by applying mixtures of natural dyestuffs in various combinations of iron- and alum-mordants. More than $60 \%$ of tested dyeings achieved acceptable fastness properties.

On the basis of the developed natural dyestuff-based dyeing procedures, a comparison was made between the effluents from processes based upon them and those based upon the current 'state-ofthe-art' techniques utilizing synthetic dyes. The comparison revealed that a lowering of the chemical load released with waste water can be expected by shifting to the plant-based dyes.

In most of the cases mordant has improved the fastness properties. Then in comparative studies between synthetic reactive and natural dyeings, it was inferred that these natural dyes have excellent potential to act as co-partner with synthetic dyes except turmeric according to their shades and fastness properties in textiles. Finally, cost analyses were also conducted for all these natural \& reactive dyeings. These results indicated that most of the natural dyeing shades were costly but some of them are closer and few were even cheaper cost wise than synthetic reactive dyeings.

\section{Conclusion}

It may be concluded that the colour components isolated from the powder Curcuma longa of contained mainly alkaloid in their molecules, and those isolated from the rhizomes of Curcuma longa contained mainly flavonoid moieties. The dyed and post mordanted samples showed better fastness properties. Therefore, the dyes obtained from native plants might be alternative sources to synthetic dyes for dyeing of natural silk and cotton. The data generated through this work may be used as a basis for studying the economic viability of producing the dyes on commercial scale.

\section{Acknowledgements}

The authors are grateful to Dept. of Microbiology, Kamarajar Govt. College, Surandai, Tirunelveli, M.S. University management for their constant support Our sincere thanks to Dr. A.J.A. Ranjit Singh, Princiapal, JP Arts and Science College, Ayikudi, Tenkasi, Tirunelveli District.

\begin{tabular}{|c|c|c|c|c|}
\hline \multirow{2}{*}{ Microorganisms } & \multicolumn{4}{|c|}{ Zone of inhibition $(\mathbf{m m})$} \\
\cline { 2 - 5 } & $\mathbf{2 0} \boldsymbol{\mu \mathbf { l }}$ & $\mathbf{4 0} \boldsymbol{\mu l}$ & $\mathbf{6 0} \boldsymbol{\mu l}$ & $\mathbf{8 0} \boldsymbol{\mu l}$ \\
\hline \multirow{2}{*}{ S. aureus } & $15.00 \pm 0.57$ & $12.66 \pm 0.66$ & $16.33 \pm 0.33$ & $12.00 \pm 0.57$ \\
\hline E. coli & $10.66 \pm 0.66$ & $14.66 \pm 0.66$ & $13.33 \pm 0.33$ & $12.66 \pm 0.66$ \\
\hline
\end{tabular}

Table 1: Antibacterial activity of Curcuma longa extracts of disc diffusion method.

\begin{tabular}{|c|c|c|c|c|}
\hline \multirow{2}{*}{ Microorganisms } & \multicolumn{4}{|c|}{ Zone of inhibition $(\mathbf{m m})$} \\
\cline { 2 - 5 } & $\mathbf{2 0} \boldsymbol{\mu l}$ & $\mathbf{4 0} \boldsymbol{\mu l}$ & $\mathbf{6 0} \boldsymbol{\mu l}$ & $\mathbf{8 0} \boldsymbol{\mu l}$ \\
\hline A.niger & $10.33 \pm 0.88$ & $12.66 \pm 0.33$ & $10.33 \pm 0.33$ & $14.00 \pm 0.57$ \\
\hline C.albicans & $11.33 \pm 0.66$ & $13.00 \pm 0.57$ & $11.33 \pm 0.66$ & $14.33 \pm 0.33$ \\
\hline
\end{tabular}

Table 2: Antifungal activity of Curcuma longa extracts of disc diffusion method.

\begin{tabular}{|c|c|c|c|c|}
\hline \multirow{2}{*}{ Microorganisms } & \multicolumn{4}{|c|}{ Zone of inhibition $(\mathbf{m m})$} \\
\cline { 2 - 5 } & & \multicolumn{4}{|c|}{ Concentration $(\boldsymbol{\mu l})$} \\
\hline Polyester & 0 & 95 & 54.5 & 100 \\
\hline Nylon & 0 & 100 & 0 & 0 \\
\hline Wool & 92.3 & 99.9 & 100 & 100 \\
\hline Silk & 65 & 0 & 90.1 & 99.9 \\
\hline Cotton & 0 & 100 & 99.9 & 99.9 \\
\hline
\end{tabular}

Table 3: Bacteria reduction percentage of dyed fabrics against $E$. coli. 
Citation: Chairman K, Jayamala M, Christy VR, Singh RAJA (2015) Phytochemical Screening and Antimicrobial Activity of Curcuma longa Natural Dye. General Med 3: 171. doi:10.4172/2327-5146.1000171

\section{References}

1. Zollinger H (1991) Colour Chemistry. VCH, Weinheim, Germany 311.

2. Sigrist MS, Pinheiro JB, Azevedo Filho JA, Zucchi MI (2011) Genetic diversity of turmeric germplasm (Curcuma longa; Zingiberaceae) identified by microsatellite markers. Genetics and Molecular Research. 10: 419-428.

3. Guinot P, Benonge I, Nicolet G, Gargadennec A, Andary C, et al. (2007) The colorants from leaves of Bischofia javanica. International Dyer 192: 31-37.

4. Sharma AA, Bansal SR, Sood A (2007) An excellent natural dye source for Mulberry silk. Colourage, 54: 45-48.

5. Tawfik S (2002) Technological evaluation of turmeric as natural dye in textile printing. Journal of the Textile Association 63: 169-175

6. Samanta AK, D Singhee. Sethia M (2003) Application of single and mixture of selected natural dyes on cotton fabric: A scientific approach. Colourage 50: 29-42.

7. Iqbal JM, Ashiq MN (2007) Adsorption of dyes from aqueous solution on activated charcoal. Journal of Hazardous Material 1: 57-66.

8. Han S, Yang Y (2005) Antimicrobial activity of wool fabric treated with curcumin Dyes and Pigments 64: 157-161.
9. Machado TB, Pinto AV, Pinto MCFR, Leal ICR, Silva MG (2003) In vitro activity of Brazilian medicinal plants, naturally occurring naphthoquinones and their analogues, against methicillin-resistant Staphylococcus aureus. Int J Antimicrob Agents 21: 279e84.

10. Amalid Mahmud-Ali, Christa Fitz-Binder, Thomas Bechtold (2012) Aluminium based dye lakes from plant extracts for textile coloration. Dyes and Pigments, 94: 533e540.

11. Gulrajani ML, Gupta D (1992) Natural Dyes and their Application to Textiles. Indian Institute of Technology, Delhi.

12. Mathur JP, Bhandari CS (2001) Physico-chemical study of dyed wool: Part-1, Bougainvillaea as wool colourant with mixed mordant. Indian Journal of Fiber Textile Research 26: 432-437.

13. Teli MD, R Paul and PD, Pardeshi (2000) Natural dyes: classification, chemistry and extraction methods. Colourage, December: 43-55.

14. Shenai VA (1984) Technology of Textile Processing, vol. VI. Sevak Publications Bombay 27.

15. Vankar PSR, Shanker SD, Mahantab, Tiwaric SC (2007) Characterisation Zollinger H. Color Chemistry. Syntheses, Properties, and Applications of Organic Dyes and Pigments. 3rd revised ed. John Wiley and Sons: New York, 2004. 